\title{
Gemcitabine and carboplatin demonstrate synergistic cytotoxicity in cervical cancer cells by inhibiting DNA synthesis and increasing cell apoptosis
}

\author{
This article was published in the following Dove Press journal: \\ OncoTargets and Therapy \\ 23 November 2013 \\ Number of times this article has been viewed
}

\author{
Guixiu Jin ${ }^{1,3}$ \\ Jing Zhao ${ }^{2}$ \\ Hongyan $\mathrm{Qi}^{2}$ \\ Meng Lou ${ }^{2}$ \\ Xia Liu ${ }^{2}$ \\ $\mathrm{Yu} \mathrm{Qu}^{3}$ \\ Lingjun Zhao ${ }^{3}$ \\ Weifeng Zhang ${ }^{3}$ \\ Jimin Shao ${ }^{2}$ \\ Huizhen Zhong ${ }^{3}$ \\ 'School of Medicine, Ningbo \\ University, Ningbo, ${ }^{2}$ Department \\ of Pathology and Pathophysiology, \\ Zhejiang University School of \\ Medicine, Hangzhou, ${ }^{3}$ Department \\ of Gynecological Oncology, Ningbo \\ Women and Children's Hospital, \\ Ningbo, People's Republic of China
}

Correspondence: Huizhen Zhong Department of Gynecological Oncology, Ningbo Women and Children's Hospital, Ningbo, Zhejiang 3/50I2,

People's Republic of China

Tel +86574 87I I 676 I

Fax +86 574 87II 676I

Email nbfeyyzhz@163.com

Jimin Shao

Department of Pathology and Pathophysiology, Zhejiang University School of Medicine, Hangzhou, Zhejiang 310058, People's Republic of China

Tel +86 57| 88208209

Fax +86 57I 88208209

Email shaojimin@zju.edu.cn
Background: The present study aims to investigate the subunit expression and enzyme activity of ribonucleotide reductase in cervical cancer patients, and detect the combined effect of the ribonucleotide reductase inhibitor gemcitabine and the chemotherapeutic agent carboplatin on cervical cancer cell lines.

Methods: Using quantitative reverse transcription polymerase chain reaction, Western blotting, and cytidine $5^{\prime}$-diphosphate reduction assays, we tested the expression and activity of ribonucleotide reductase in cervical cancer patients. The antitumor activity of gemcitabine and/or carboplatin treatments to $\mathrm{SiHa}$ and CaSki human cervical cancer cell lines were assessed by Cell Counting Kit-8 viability assay, EdU incorporation assay, immunofluorescence assay, flow cytometry assay, and Western blotting methods. Additionally, synergistic efficacy was quantitatively analyzed using a combination index based on the Chou-Talalay method.

Results: The mRNA levels of three ribonucleotide reductase subunits were all upregulated in the cervical cancer tissues compared with normal tissues $(P<0.0001)$. Consistently, the protein expression and enzyme activity of ribonucleotide reductase were also increased in the cervical cancer tissues. Interestingly, gemcitabine inhibited DNA synthesis and carboplatin induced DNA damage. Further, the combined drug regime had a significant synergistic effect on inhibiting cervical cancer cell viability $\left(\log _{10}[\operatorname{combination}\right.$ index $\left.]<0\right)$ via enhanced DNA damage and cell apoptosis.

Conclusion: The expression and activity of ribonucleotide reductase was increased in cervical cancer. Our study demonstrated the synergistic cytotoxicity of gemcitabine and carboplatin, through inhibiting DNA synthesis and increasing cell apoptosis in cervical cancer cell lines. This evidence might provide a rational clue of their combined application to improve cervical cancer treatment.

Keywords: cervical cancer, ribonucleotide reductase, gemcitabine, carboplatin

\section{Introduction}

Cervical cancer remains a serious health problem, with an annual incidence of 530,000 cases and 275,100 deaths in females worldwide. ${ }^{1}$ More than $80 \%$ of cervical cancer is squamous cell carcinoma in pathologic classification. ${ }^{1}$ Surgery is the main treatment for small stage I cervical cancers, but for patients with advanced, recurrent, or metastatic cervical cancer, chemotherapy remains the standard treatment. ${ }^{2}$ Platinum compounds form bifunctional crosslinks with DNA, and DNA interstrand or intrastrand crosslinks induce DNA damage, including double-strand DNA breaks, 
and ultimately result in cell death. ${ }^{3}$ Historically, cisplatin is regarded as the primary chemotherapy for advanced or metastatic cervical cancer, but the response rate is approximately $20 \% .{ }^{4}$ Carboplatin has activity in cervical cancer comparable with that of cisplatin, but has better chemical stability and less systemic toxicity. ${ }^{5}$ With the encouraging Japan Clinical Oncology Group data, carboplatin may ultimately replace cisplatin in future practice and/or clinical trials. ${ }^{6}$ A major clinical problem associated with platinum therapy is that although many patients may be initially responsive to it, they often relapse and become refractory to further single-agent platinum treatment.

The formation and growth of cancer cells are related to the synthesis of the DNA. Ribonucleotide reductase (RR) is an enzyme that catalyzes the reduction of ribonucleotides to their corresponding deoxyribonucleotides, which are the building blocks for DNA synthesis and repair in all living cells. ${ }^{8}$ Human RR is composed of the catalytic large subunit RRM1 and the regulatory small subunit RRM2 or RRM2B. ${ }^{8}$ Because RR plays a critical role in DNA synthesis, it is considered an important therapeutic target for cancer chemotherapy. ${ }^{9}$

Gemcitabine (2,2-difluorodeoxycytidine; $\mathrm{dFdC}$ ), currently the most potent $\mathrm{RR}$ inhibitor, has been widely used in treatment and assessment of the clinical benefit of different therapeutic approaches and combinations with other anticancer drugs or radiation therapy for solid tumors, including non-small cell lung cancer, pancreatic cancer, breast, ovarian, bladder, and head and neck cancer, as well as hematologic malignancies. ${ }^{10}$ The compound $\mathrm{dFdC}$ is metabolized intracellularly to generate $5^{\prime}$-diphosphate (dFdCDP) and 5 'triphosphate (dFdCTP) nucleosides. While dFdCDP binds to RRM1 and inhibits RR activity, causing a reduction of the cellular dNTP concentration, dFdCTP competes with natural dCTP for incorporation into the replicating DNA, leading to DNA strand termination. The decrease of intracellular dCTP accelerates phosphorylation of $\mathrm{dFdC}$ to its two active forms, reduces metabolic clearance of gemcitabine nucleotides, and enhances incorporation of dFdCTP into DNA. This self-potentiation mechanism should account for the high anticancer efficacy of gemcitabine. ${ }^{11,12}$

Combination therapy based on drugs with different mechanisms of action is a major strategy for improving drug responses and cure rates and for overcoming resistance. Platinum agents and gemcitabine are ideal candidates for use in combination regimens because of their different but complementary biochemical mechanisms of action, similar antitumor activity profiles, and nonoverlapping side effect profiles. ${ }^{13}$ There is clinical evidence indicating that the combination of platinum agents and gemcitabine improves response rates when compared with single platinum agents. ${ }^{14,15}$ However, the effect and mechanism of action of their combination has not been experimentally investigated previously in cervical cancer.

In this study, we examined the expression and enzyme activity of three subunits of RR in patients with cervical cancer, and explored the combined effect of the RR inhibitor gemcitabine and the chemotherapeutic agent carboplatin on cervical cancer cells.

\section{Materials and methods Drugs, cell lines, and clinical tissue samples}

Gemcitabine $\left(\right.$ Gemzar $\left.^{\circledR}\right)$ was purchased from Eli Lilly France (Fegersheim, France). Carboplatin $\left(\right.$ Paraplatin $^{\circledR}$ ) was obtained from Bristol-Myers Squibb Srl (Latina, Italy). SiHa and CaSki human cervical cancer cell lines (American Type Culture Collection, Manassas, VA, USA) were maintained in RPMI-1640 medium (Gibco, Carlsbad, CA, USA) supplemented with $10 \%$ fetal bovine serum, $2 \mathrm{mM} \mathrm{L}$-glutamine, and $100 \mathrm{U} / \mathrm{mL}$ penicillin-streptomycin at $37^{\circ} \mathrm{C}$ in a humidified atmosphere of $5 \% \mathrm{CO}_{2}$. Paired surgical specimens of cancer and adjacent normal tissues were collected from 45 patients with cervical cancer at NingBo Women and Children's Hospital from 2011 to 2012 following approval from The Scientific Research Institutional Review Board of Ningbo Women and Children's Hospital. Tissue samples from patients with cervical cancer who received preoperative radiation or chemotherapy were excluded. All tissues were stored at $-80^{\circ} \mathrm{C}$ immediately after excision.

\section{RNA extraction and quantitative RT-PCR}

Total RNA was isolated from clinical tissue samples with a total RNA isolation kit (AP-MN-MS-RNA, Axygen Scientific Inc., Union City, CA, USA) as described by the manufacturer. Single-strand complementary DNA was reverse-transcribed from 450 ng of total RNA using a first-strand complementary DNA synthesis kit (Takara Bio Inc., Shiga, Japan). Quantitative reverse transcription polymerase chain reaction (RT-PCR) was performed on an ABI Prism 7500 system (Applied Biosystems, Foster City, CA, USA) using SYBR Green Premix Ex Taq (TaKaRa Bio Inc., Shiga, Japan). The primers were as follows: RRM1 (sense, 5'-GGA GAC TAA TCA GGA CTG GT-3', antisense, 5'-CAA CTT TGC GGA CAC GAC CT-3'), RRM2 (sense, 5'-GCA GCA AGC GAT GGC ATA GT-3', antisense, 5'-GGG CTT CTG 
TAA TCT GAA CTT C-3'), and RRM2B (sense, 5'-TAA ACA GGC ACA GGC TTC CT-3', antisense, 5'-CGC TCC ACC AAA TTT TCA TT-3'). For thermal cycling, the following conditions were applied: 10 minutes at $95^{\circ} \mathrm{C}$, then 40 cycles of 15 seconds at $95^{\circ} \mathrm{C}$ and 2 minutes at $60^{\circ} \mathrm{C}$. $\beta$-Actin was used as the loading control.

\section{Western blotting analysis}

Total tissue proteins were extracted as follows: clinical tissue specimens were triturated in buffer $(50 \mathrm{mM}$ Tris- $\mathrm{HCl}$, $\mathrm{pH} 7.6,2 \mathrm{mM}$ DTT, and protease inhibitors) and centrifuged at $16,000 \mathrm{~g}$ and $4^{\circ} \mathrm{C}$ for 30 minutes. The supernatant was then collected for $10 \%$ sodium dodecyl sulfate polyacrylamide gel electrophoresis and Western blotting analysis. Primary antibodies for RRM1, RRM2, and RRM2B (Santa Cruz Biotechnology, Santa Cruz, CA, USA) were used at 1:1,000 dilutions. GAPDH (Santa Cruz) antibody was used as a loading control. Secondary antibodies were purchased from Li-Cor Biosciences (Lincoln, NE, USA), and the blots were visualized and quantified using a Li-Cor Odyssey Infrared Imaging scanner.

\section{RR activity assay}

RR activity in clinical tissue samples was assayed based on the Steeper and Steuart CDP reduction method ${ }^{16}$ with modifications as described previously. ${ }^{17,18}$ Briefly, the protein supernatants of total tissue lysates were collected as indicated above. Sequentially, $1 \%$ streptomycin sulfate precipitation and $40 \%$ saturated $\left(\mathrm{NH}_{4}\right)_{2} \mathrm{SO}_{4}$ sedimentation were performed, and the supernatants obtained were ultrafiltered through Amicon ${ }^{B}$ ultra-15 centrifugal filters (Millipore, MA, USA) with $50 \mathrm{mM}$ HEPES, pH 7.4, and $100 \mathrm{mM} \mathrm{KCl}$. After quantification, the protein samples were added to $100 \mu \mathrm{L}$ of reaction mixture containing $0.125 \mathrm{mM}\left[{ }^{3} \mathrm{H}\right] \mathrm{CDP}(24 \mathrm{Ci} / \mathrm{mmol}), 50 \mathrm{mM}$ HEPES (pH 7.2), 6 mM DTT, 4 mM MgOAc, 2 mM ATP, $0.05 \mathrm{mM} \mathrm{CDP}$, and $100 \mathrm{mM} \mathrm{KCl}$. After incubation at $37^{\circ} \mathrm{C}$ for 30 minutes and dephosphorylation, the samples were analyzed by high-performance liquid chromatography and liquid scintillation counting. The enzyme activity of RR was presented as follows: $\mathrm{RR}$ activity $=\mathrm{dCDP} /(\mathrm{CDP}+\mathrm{dCDP}) \times 100 \%$.

\section{Cell viability assay}

Cell viability was detected using the Cell Counting Kit-8 assay (CCK-8, Dojindo Laboratories, Kumamoto, Japan). Briefly, SiHa and CaSki cells were dispensed in triplicate into 96-well plates $\left(5 \times 10^{3}\right.$ cells/well $)$ and incubated overnight at $37^{\circ} \mathrm{C}$. The cells were then treated with varied concentrations of gemcitabine or/and carboplatin. After 72 hours, $10 \mu \mathrm{L}$ of CCK-8 kit solution was added to the cells, which were then incubated for 2.5 hours at $37^{\circ} \mathrm{C}$. Absorbance was then measured by a microplate reader at $450 \mathrm{~nm}$ (model ELX800, Bio-Tek, Winooski, VT, USA). Data were obtained from at least three separate experiments done in triplicate.

\section{EdU incorporation assay}

The inhibitory effect of gemcitabine on DNA synthesis was assessed using the Cell-Light EdU (5-ethynyl-2'deoxyuridine) DNA Cell Proliferation Kit (RiboBio Co, Guangzhou, People's Republic of China). SiHa cells $\left(2.5 \times 10^{4}\right.$ cells/well $)$ were seeded in 96-well plates in triplicate and exposed to gemcitabine for 12 hours, and then treated with $50 \mu \mathrm{mol} / \mathrm{L}$ of EdU for 2 hours at $37^{\circ} \mathrm{C}$. After being fixed with $4 \%$ paraformaldehyde for 30 minutes, the cells were treated with $0.5 \%$ Triton X-100 for 20 minutes and washed with phosphate-buffered saline three times. The cells were then exposed to $100 \mu \mathrm{L}$ of $1 \times$ Apollo $^{\circledR}$ reaction cocktail for 30 minutes and incubated with $1 \times$ Hoechst 33342 to stain the cell nuclei for 30 minutes. Images of the cells were captured with a fluorescence microscope (Nikon, Tokyo, Japan). ImageJ software (National Institutes of Health, Bethesda, MD, USA) was used to count the fluorescent points.

\section{$\gamma-\mathrm{H} 2 \mathrm{AX}$ detection}

For immunofluorescence analysis, SiHa cells were grown on glass coverslips in six-well plates. After treatment, the cells were washed three times with cold phosphate-buffered saline and fixed in 4\% paraformaldehyde for 15 minutes, and then blocked with $5 \%$ bovine serum albumin for one hour at room temperature followed by incubation with primary antibodies against $\gamma-\mathrm{H} 2 \mathrm{AX}$ mouse (Upstate/Millipore) at $4^{\circ} \mathrm{C}$ overnight. After rinsing in phosphate-buffered saline, the cells were incubated with fluorescein isothiocyanate (FITC)-conjugated secondary antibodies for one hour at room temperature. The cells were then stained with 4',6-diamidino-2-phenylindole (DAPI) and viewed using a fluorescence microscope (AX70, Olympus, Tokyo, Japan).

For Western blotting analysis, total proteins were extracted from the cell lines. Anti-phospho-H2AX (Ser 139) antibody was purchased from Upstate. GAPDH antibody was used as a loading control. Secondary antibodies were purchased from Li-Cor Biosciences, and blots were visualized and quantified using a Li-Cor Odyssey ${ }^{\circledR}$ Infrared Imaging scanner.

\section{Flow cytometry measurements}

$\mathrm{SiHa}$ cells were seeded in $35 \mathrm{~mm}$ dishes at a density of $3 \times 10^{5}$ cells, incubated for 24 hours at $37^{\circ} \mathrm{C}$, and treated with 
gemcitabine or/and carboplatin at the indicated concentrations for 72 hours. They were then washed with cold phosphatebuffered saline twice, followed by staining with Annexin V-FITC/propidium iodide (KeyGEN, Nanjing, People's Republic of China). Apoptotic cells were analyzed immediately on a FACSCalibur flow cytometer (Becton Dickinson, San Jose, CA, USA) using the CellQuest 3.0 software system.

\section{Statistical analysis}

To determine the nature of the interaction between gemcitabine and carboplatin, the data from the cell viability assays were analyzed based on the Chou-Talalay method using CalcuSyn version 2.0 software (Biosoft, Cambridge, UK). ${ }^{19,20}$ Interaction between the drugs was quantified by determining a combination index (CI). Using this method, CI $<1$ indicates synergy, $\mathrm{CI}=1$ indicates an additive effect, and $\mathrm{CI}>1$ indicates antagonism. The EdU incorporation assay, $\gamma$-H2AX detection, and cell apoptosis assay were performed in three separate experiments and the data are expressed as the mean \pm standard deviation. The Student's $t$-test was used for the statistical analysis and $P<0.05$ was considered to be statistically significant. The statistical analyses were performed using Statistical Package for the Social Sciences version 13 software (SPSS Inc., Chicago, IL, USA).

\section{Results}

\section{RR subunit expression and enzyme activity were upregulated in human cervical cancer tissues}

In order to investigate the roles of RR in cervical cancer, we examined the mRNA levels of the three RR subunits in the paired cancer and adjacent normal tissues from 45 cases of cervical cancer by quantitative RT-PCR. As shown in Figure 1A, the mRNA levels of RRM1, RRM2, and RRM2B were all upregulated in the cancer tissues compared with normal tissues $(P<0.0001)$. In addition, we also randomly measured the subunit protein levels and enzyme activity of $\mathrm{RR}$ in clinical tissues from eight cases. The results showed that both the activity and subunit protein levels of RR were consistently increased in these cancer tissues when compared with normal tissues (Figure 1B and C).

\section{Gemcitabine decreased cell viability and inhibited DNA synthesis in cervical cancer cells}

Using CCK-8 viability assays, we determined the growth inhibitory effect of gemcitabine on $\mathrm{SiHa}$ and CaSki cervical cancer cells in which RR are overexpressed. Cell viability was suppressed by gemcitabine in a dose-dependent manner (Figure 2A), and the calculated $\mathrm{IC}_{50}$ values for gemcitabine in $\mathrm{SiHa}$ and CaSki cells were $29.6 \mu \mathrm{mol} / \mathrm{L}$ and $23.8 \mu \mathrm{mol} / \mathrm{L}$, respectively. EdU incorporation assays were performed to detect whether gemcitabine could affect DNA synthesis in cervical cancer cells. In Figure $2 \mathrm{~B}$ and $\mathrm{C}$, the number of EdU-incorporated cells were decreased by treatment with gemcitabine when compared with the control. These results demonstrate that gemcitabine inhibited DNA synthesis and reduced proliferation of the cervical cancer cells.

\section{Carboplatin reduced cell viability and induced DNA damage in cervical cancer cells}

We tested the ability of carboplatin to suppress the growth of cervical cancer cells. The cell viability assays showed that carboplatin significantly inhibited growth of $\mathrm{SiHa}$ and CaSki cells (Figure 3A). The $\mathrm{IC}_{50}$ values for carboplatin were $142.4 \mu \mathrm{mol} / \mathrm{L}$ and $103 \mu \mathrm{mol} / \mathrm{L}$ for the two cell lines, respectively. In addition, to validate whether the cytotoxicity of carboplatin was associated with DNA damage, we examined phosphorylated H2AX (Ser-139, $\gamma$-H2AX) expression in SiHa cells by immunofluorescence assay. $\gamma$-H2AX has many functions and is best known for its role in DNA double-strand break repair. The results confirm that $\mathrm{H} 2 \mathrm{AX}$ was phosphorylated after exposure to carboplatin in a dose-dependent manner, and suggest that carboplatin induced DNA damage in cervical cancer cells (Figure 3B and C).

\section{Synergistic inhibitory effect of gemcitabine and carboplatin in cervical cancer cell lines}

In order to assess whether gemcitabine and carboplatin have a synergistic effect, the SiHa and CaSki cervical cancer cells were treated with serial dilutions of the two drugs either alone or in combination for 72 hours (Figure 4A). The concentrations of gemcitabine and carboplatin maintained a constant equipotent ratio, ie, a 1:5 ratio for $\mathrm{SiHa}$ cells and a 1:4 ratio for CaSki cells, according to their $\mathrm{IC}_{50}$ values for the two cell lines. Gemcitabine and carboplatin were exposed at the same time in the combination group. The results show a dose response by the two cervical cancer cell lines to the treatments of gemcitabine and carboplatin either alone or in combination. The data were quantitatively analyzed using a CI based on the Chou-Talalay method. As shown in Figure 4B, combined treatment with gemcitabine and 
A
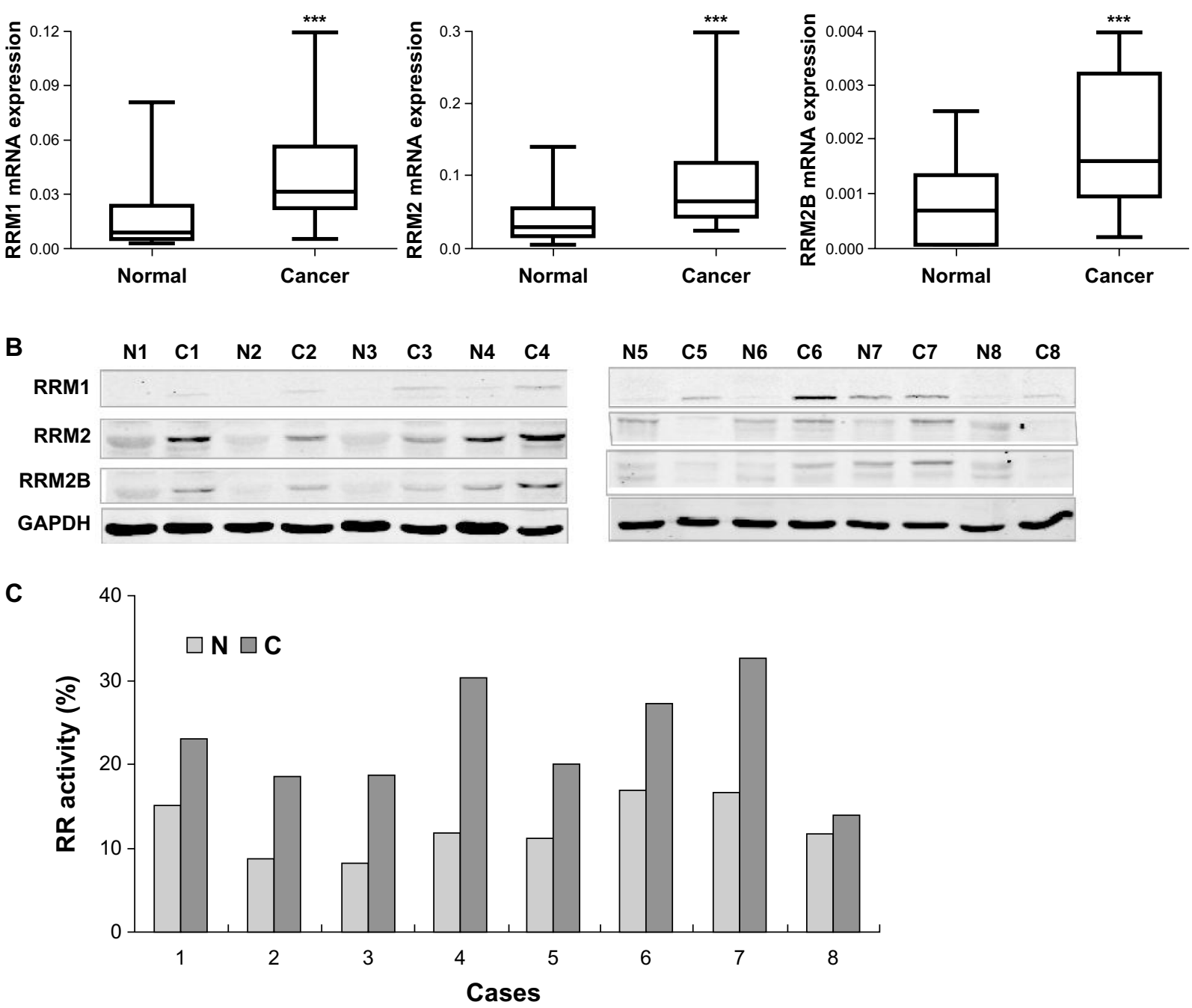

Figure I Expression and enzyme activity of three subunits of RR were upregulated in clinical cervical cancer tissues. (A) Levels of RRMI/ $\beta$-actin, RRM2/ $\beta$-actin, and RRM2B/ $\beta$-actin in paired cervical cancer and adjacent normal tissues from 45 cervical cancer patients. Nonparametric paired (Wilcoxon signed-rank) testing indicated significantly higher levels of RRMI, RRM2, and RRM2B mRNA expression in cancer tissues compared with normal tissues. ***P $<0.000$ I. (B) Western blot results for RRMI, RRM2, and $R R M 2 B$ protein levels in the paired cancer $(C)$ and adjacent normal $(N)$ tissues from eight representative cervical cancer patients. (C) RR enzyme activity measured in paired cancer and adjacent normal tissues from eight representative cervical cancer patients.

Abbreviations: RR, ribonucleotide reductase; RRMI, ribonucleotide reductase large subunit MI ; RRM2, ribonucleotide reductase small subunit M2; RRM2B, ribonucleotide reductase small subunit M2B.

carboplatin yielded significantly greater growth inhibition than either agent used alone, ie, showed synergistic cytotoxicity in both SiHa and CaSki cells $\left(\log _{10}[\mathrm{CI}]<0\right)$.

\section{Gemcitabine synergized the cytotoxicity of carboplatin in cervical cancer cells by enhancing DNA damage and cell}

\section{apoptosis}

To investigate the mechanism of the synergistic effect observed with the gemcitabine and carboplatin combination, we detected $\gamma$-H2AX expression in SiHa cells by immunofluorescence assay. The results show that the number of
$\gamma$-H2AX-positive cells increased after carboplatin exposure, which was significantly promoted by the combined treatment of gemcitabine (Figure 5A and B). Western blotting analysis of $\gamma$-H2AX expression also demonstrated that gemcitabine plus carboplatin significantly increased $\gamma$-H2AX protein expression in SiHa cells. All these results suggest that combined gemcitabine and carboplatin treatment resulted in increasing DNA damage in SiHa cells (Figure 5C).

The combined effect of gemcitabine plus carboplatin was further evaluated by Annexin V/FITC staining followed by flow cytometry analysis. As shown in Figure 5D and E, the percentage of Annexin V-positive cells was synergistically increased by the combination of gemcitabine and carboplatin 
A

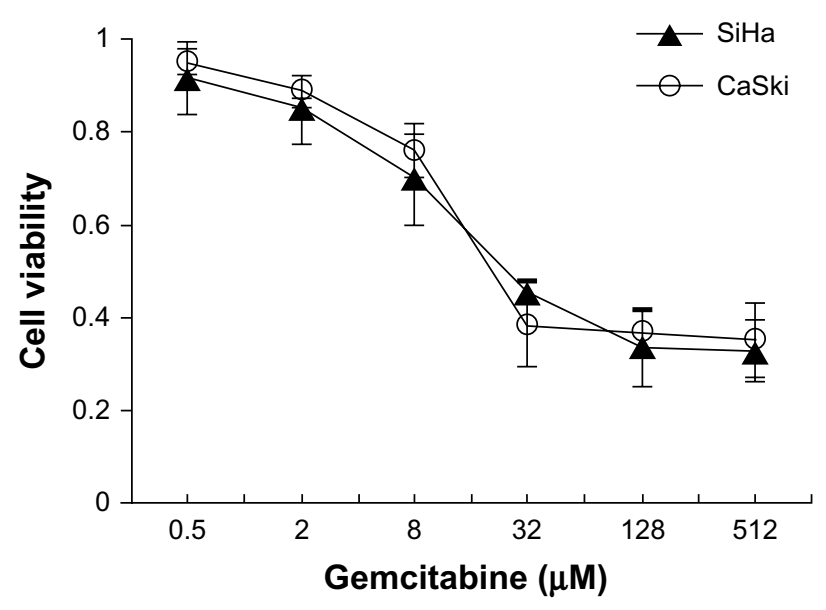

C

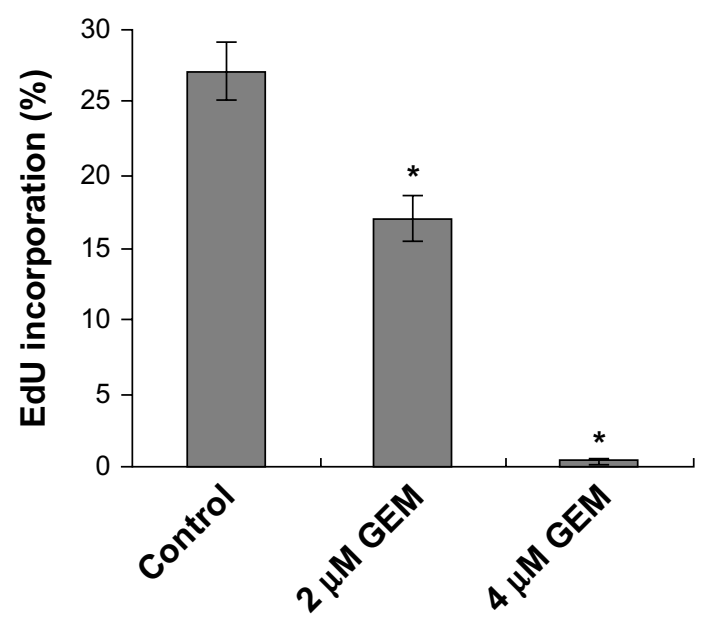

B
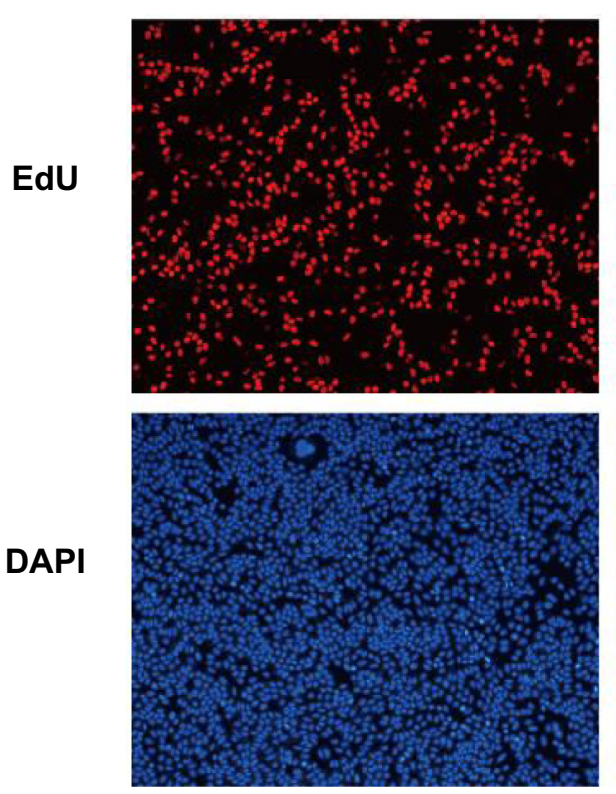

$2 \mu \mathrm{M}$ GEM
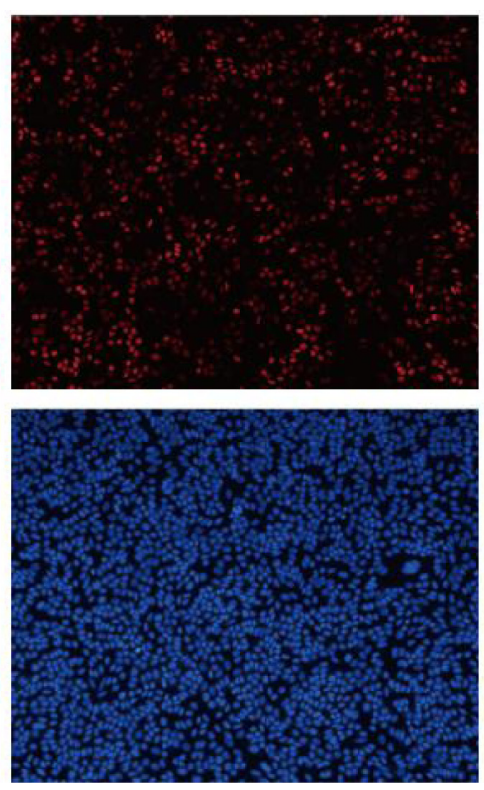

$4 \mu \mathrm{M}$ GEM
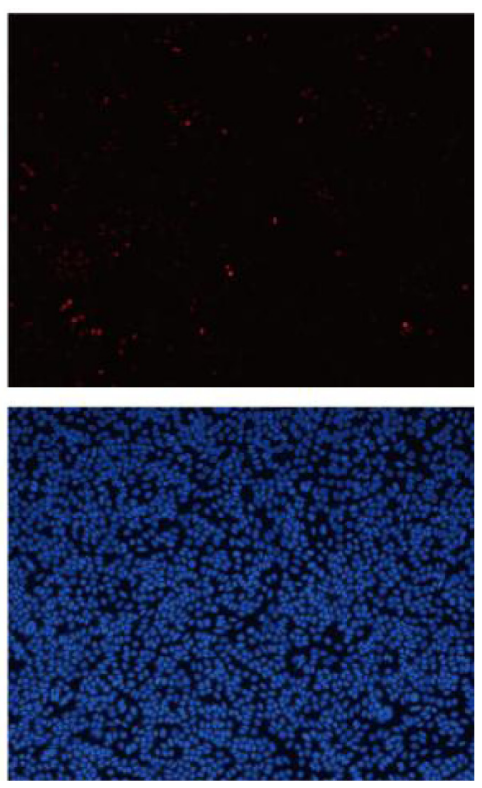

Figure 2 Gemcitabine decreased cell viability and inhibited DNA synthesis in cervical cancer cells. (A) Cells were treated with the indicated concentrations of gemcitabine for 72 hours, and cell viability was measured with Cell Counting Kit-8 viability assays. (B) SiHa cells were exposed to gemcitabine (0, 2 , and $4 \mu$ mol/L) for I 2 hours. The percentage of EdU (5-ethynyl-2'-deoxyuridine) incorporation was calculated as the number of EdU-positive nuclei (red) divided by the total nuclei (blue), the total nuclei were counterstained with DAPI. (C) We selected ten visual fields under the fluorescent microscope and calculated more than 10,000 cells for each well. Counting was carried out by ImageJ software. $* P<0.05$ for the treatment compared with the control.

Abbreviations: GEM, gemcitabine; DAPI, 4',6-diamidino-2-phenylindole.

$(P<0.05)$. The data indicate that gemcitabine and carboplatin enhance cell apoptosis in cervical cancer cells. Taken together, gemcitabine and carboplatin exhibit synergistic cytotoxicity in cervical cancer cells by increasing DNA damage and cell apoptosis.

\section{Discussion}

The uncontrolled proliferation and growth of cancer cells requires extra dNTPs for DNA synthesis. Therefore, an increase in RR activity is necessary because it helps to provide excess dNTPs for DNA replication in cancer cells. Clinical studies based on quantitative RT-PCR, immunohistochemistry, and Western blotting have demonstrated that RR subunits overexpression were involved in many types of tumors. ${ }^{21-24}$ Kunos et al investigated the immunohistochemical expression of three RR subunits in 18 paired benign and cancerous tissues of the uterine cervix. They found that cervical cancer tissues uniformly overexpress RRM2, and that cancer relapse rates are high and disease-free intervals are shorter when RRM1 and RRM2B are simultaneously 
A

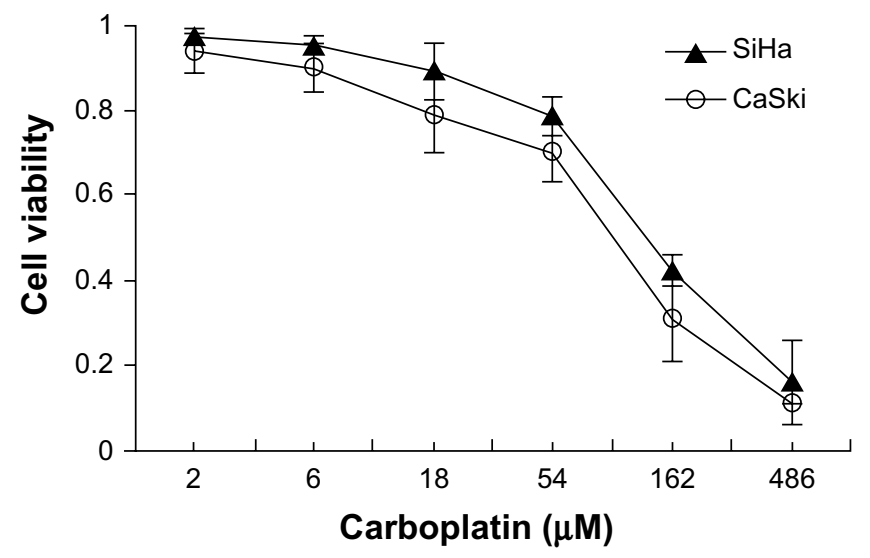

C

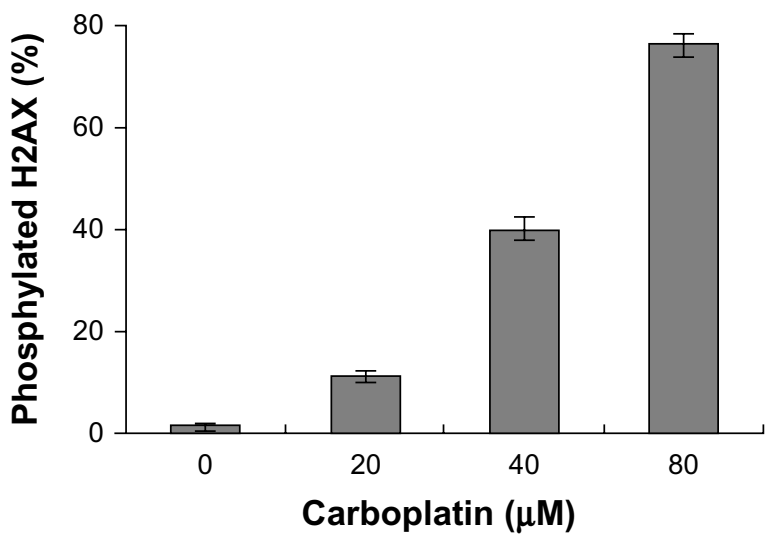

B Carboplatin $(\mu \mathrm{M})$

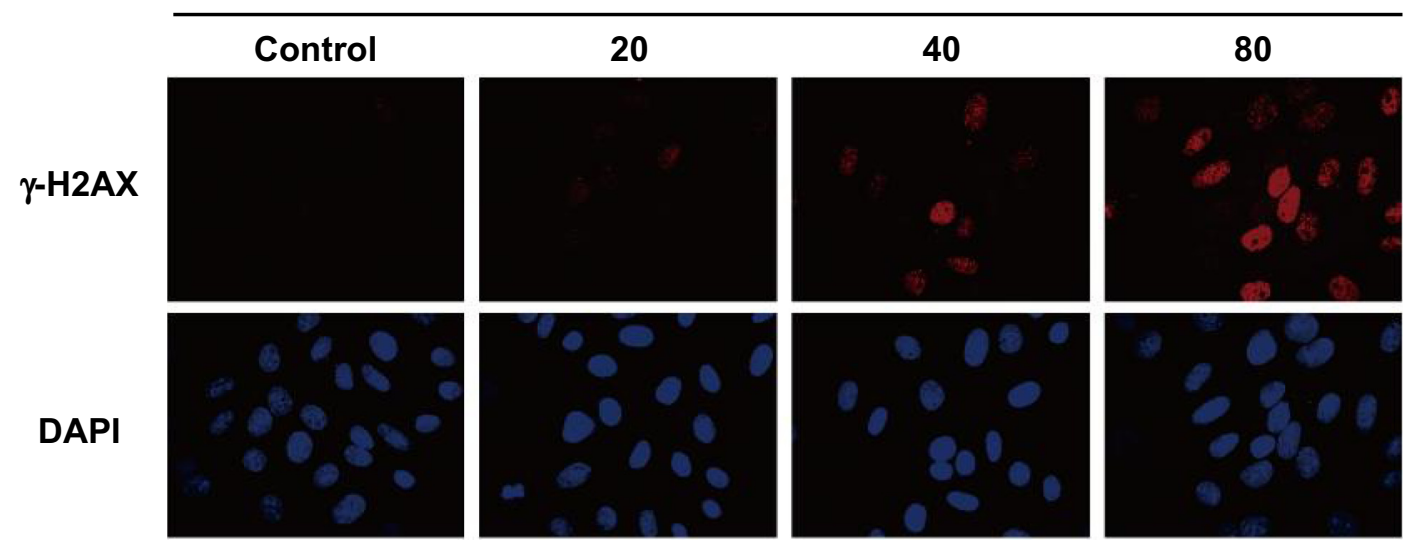

Figure 3 Carboplatin reduced cell viability and induced DNA damage in cervical cancer cells. (A) SiHa and CaSki cells were treated with the indicated concentrations of carboplatin for 72 hours, and cell viability was measured by Cell Counting Kit-8 viability assay. (B) Carboplatin induced DNA damage in SiHa cells. SiHa cells were exposed to 20,40 , and $80 \mu \mathrm{mol} / \mathrm{L}$ carboplatin for 12 hours, respectively. Immunofluorescence analysis was used to detect nuclear $\gamma$-H2AX foci formation with anti-H2AX antibody (red, fluorescein isothiocyanate). Nuclei were counterstained with DAPI (blue). (C) $\gamma$-H2AX-positive cells were counted under a fluorescent microscope. We calculated more than I,000 cells for each well. Quantitative data are represented the mean \pm standard deviation of three individual experiments.

Abbreviation: DAPI, 4',6-diamidino-2-phenylindole.

overexpressed..$^{25}$ Here, we not only showed that the expression levels of the three RR subunits were increased, but also, for the first time, suggest that the enzyme activity of RR is substantially upregulated in cancerous tissues in comparison with adjacent normal tissues in patients with cervical cancer (Figure 1). The results suggest that upregulation of RR is probably involved in the development of cervical cancer.

It has been reported that overexpression of RRM1 is negatively related to tumorigenesis and metastasis in human and mouse lung cancer cell lines by inducing PTEN expression and reducing focal adhesion kinase phosphorylation. ${ }^{26}$ RRM2 has been shown to play a critical role in enhancing invasion and metastasis in colorectal, bladder, gastric, and other cancers. ${ }^{22,27,28}$ However, the role of RRM2B in the development of cancer is controversial. RRM2B has been shown to suppress invasion and metastasis in colorectal cancer, and its expression is associated with a better survival prognosis in patients with colorectal cancer. ${ }^{29}$ However, in squamous cell carcinoma of the esophagus, RRM2B expression was significantly correlated with depth of invasion, lymph node metastasis, stage, and poor prognosis. ${ }^{30}$ Accordingly, these findings reveal that subunit expression of RR is closely associated with tumor progression, invasion, and metastasis.

Platinum compounds are generally regarded as first-line chemotherapy in recurrent or metastatic cervical cancer. Clinical evidence suggests that a platinum-based combination improves response rates and prolongs survival when compared with platinum alone. ${ }^{31}$ Previously, Hernández et al reported that the combination of cisplatin and gemcitabine increased cytotoxicity in cervical cancer cells, ${ }^{32}$ and clinical trials showed that the combination of gemcitabine and cisplatin was tolerated, achieved enhanced response rates, 

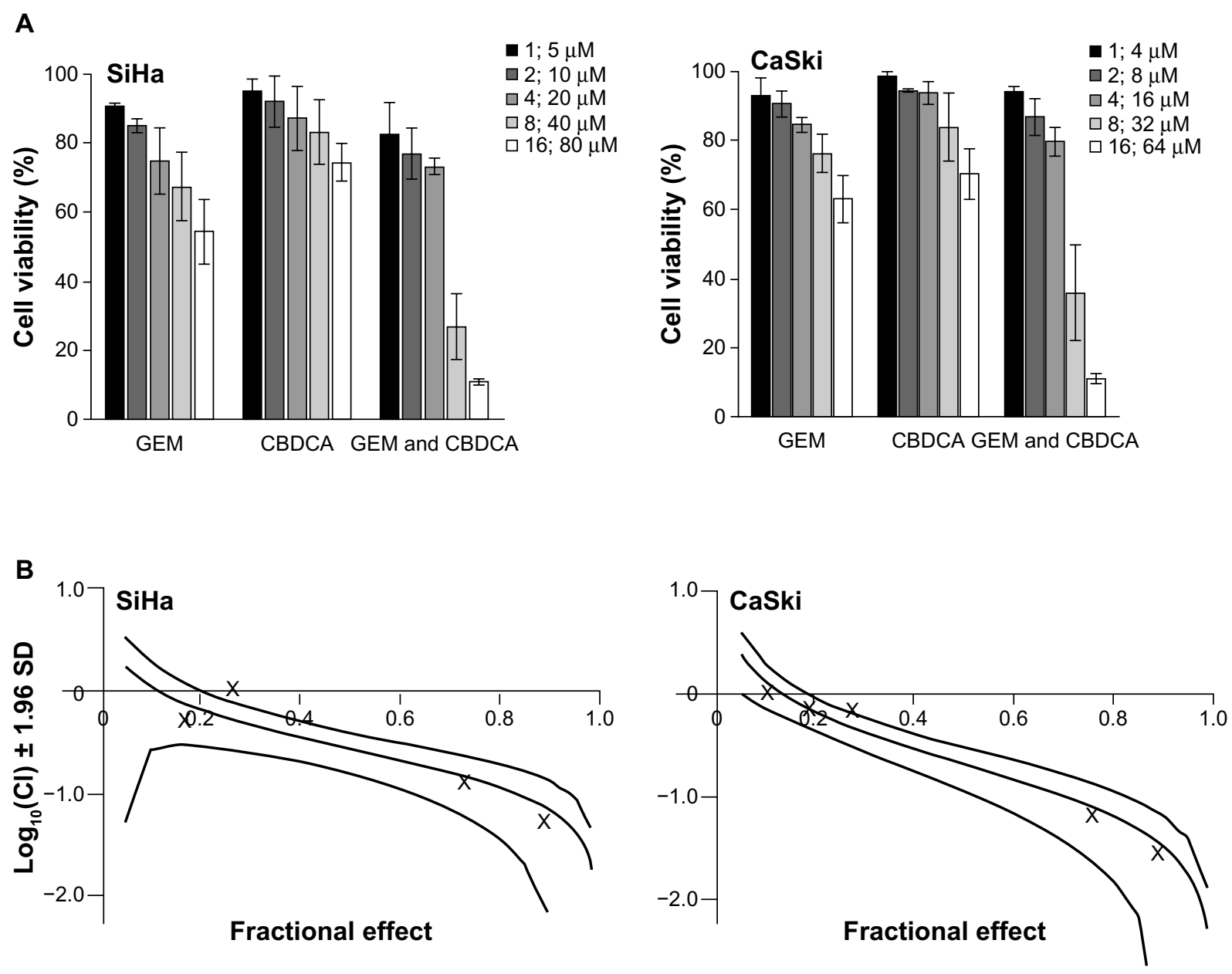

Figure 4 Synergistic cytotoxicity of gemcitabine combined with carboplatin in cervical cancer cell lines. (A) SiHa and CaSki cells were seeded into 96-well plates and treated with gemcitabine or/and carboplatin at the indicated concentrations. After 72 hours, cell viability was measured using the Cell Counting Kit-8 viability assay. The data shown represent the mean \pm standard deviation $(n=3)$. (B) The synergistic effect of gemcitabine combined with carboplatin was quantitatively analyzed with a $\mathrm{Cl}$ and expressed as $\log _{10}(\mathrm{Cl})$ versus fractional effect. Where calculable, $95 \%$ confidence intervals are shown.

Abbreviations: DAPI, 4',6-diamidino-2-phenylindole; GEM, gemcitabine; CBDCA, carboplatin; Cl, combination index; SD, standard deviation.

and prolonged survival in patients with cervical squamous carcinoma. ${ }^{14,15,33}$ The National Comprehensive Cancer Network guidelines (version 2.2013) recommend first-line combination therapies including cisplatin/gemcitabine (category 2B) for recurrent or metastatic cervical cancer. However, the effect of combination of gemcitabine and carboplatin on cervical cancer cells has not been experimentally investigated before. Here, we demonstrated that gemcitabine plus carboplatin had a synergistic inhibitory effect on cervical cancer cells $\left(\log _{10}[\mathrm{CI}]<0\right.$, Figure 4$)$. Used separately gemcitabine inhibited DNA synthesis and carboplatin induced DNA damage (Figures 2 and 3), and gemcitabine plus carboplatin enhanced the DNA-damaging effects and cell apoptosis in cervical cancer cells (Figure 5).

The synergistic effect of this combined drug regime could be attributed to the different but complementary mechanisms of action of the drugs involved. Carboplatin causes cellular DNA strand breaks and activates the DNA damage-responsive ATM/ATR signaling pathways, ${ }^{34}$ which induces cell cycle arrest and DNA repair or cell apoptosis depending on the extent of the DNA damage. ${ }^{35}$ On the other hand, gemcitabine inhibits DNA synthesis by reducing RR activity and blocking DNA strand elongation, which simultaneously prevents repair of carboplatin-induced DNA damage. Ultimately, the combined treatment synergistically suppresses cell proliferation and leads to cell death.

Other RR inhibitors, such as triapine, are also reported to increase both radiation and chemotherapy sensitivity through a mechanism involving blocking RR activity which results in sustained DNA damage in cervical cancer cells. ${ }^{36}$ Further, the synergistic cytotoxicity between cisplatin and gemcitabine has been observed in human ovarian cancer cell lines and head and neck cancer xenografts, ${ }^{13,37}$ and one 


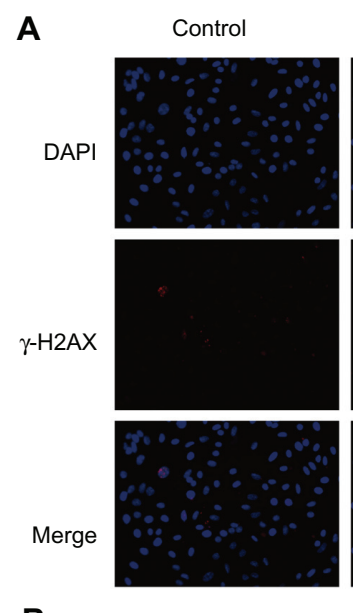

B

D

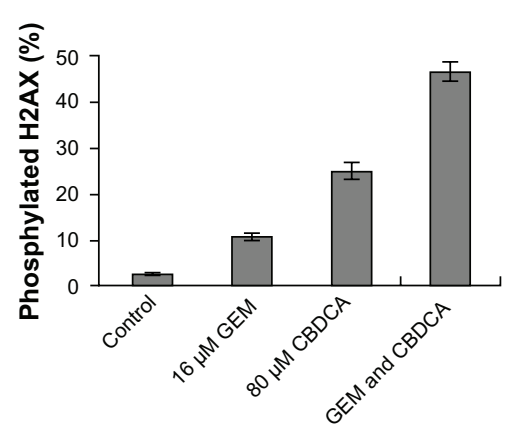

Control

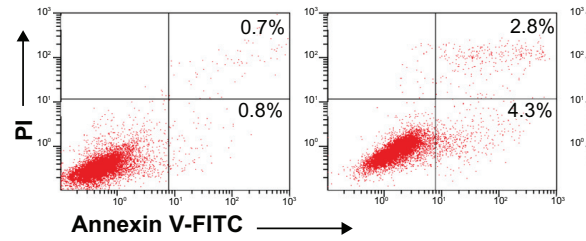

$E$
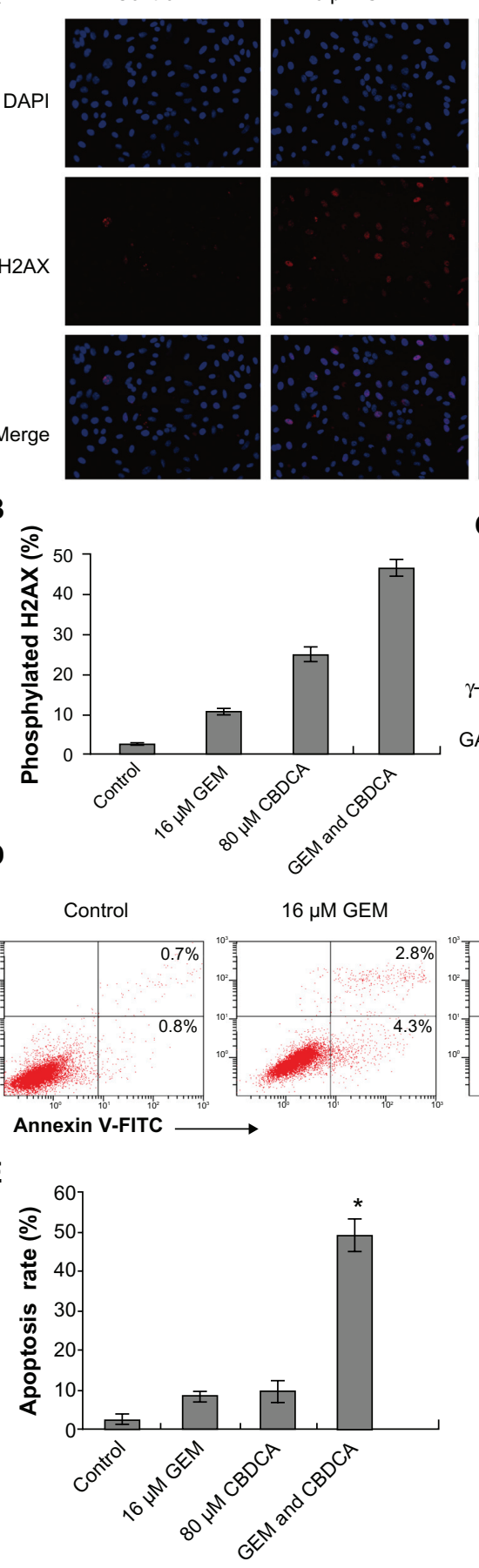

$80 \mu \mathrm{M}$ CBDCA
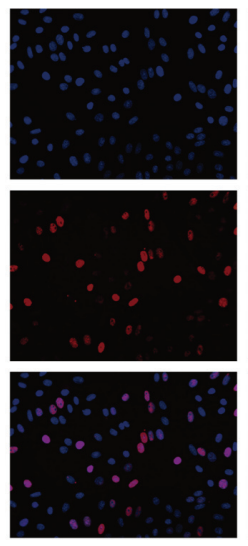

C
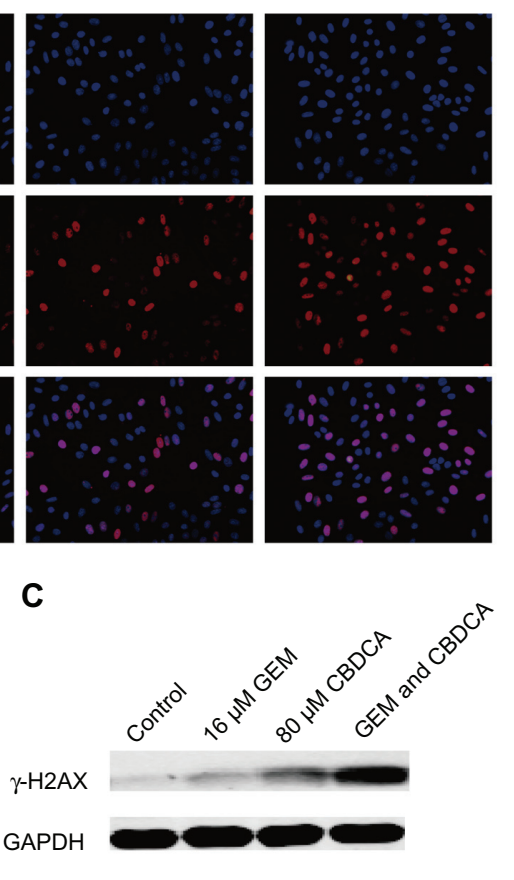

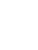
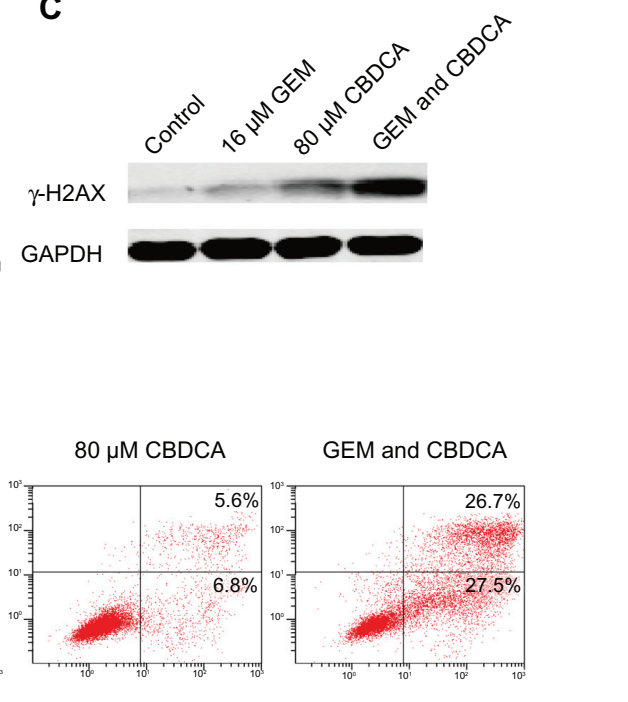
arm (cisplatin/paclitaxel) in GOG 204. However, if a patient has contraindications or is not a candidate for taxanes, carboplatin and gemcitabine could be a reasonable alternative option.

In summary, we demonstrated that subunit expression and enzyme activity of RR were increased in most cervical cancer tissues, and the RR inhibitor gemcitabine synergized the cytotoxicity of carboplatin by enhancing DNA damage and cell apoptosis in cervical cancer cells. Our study might provide evidence for the combined use of gemcitabine and carboplatin in the treatment of cervical cancer.

\section{Acknowledgments}

This work was partly supported by the Preferential Society Development Program of Ningbo Municipal Science and Technology Bureau (2009C50001), the National Natural Science Foundation of China (30873094 and 30770831), the 863 National High Technology Research and Development Program of China (2012AA020206), and the KC Wong Magna Fund at Ningbo University.

\section{Disclosure}

The authors report no conflicts of interest in this work.

\section{References}

1. Jemal A, Bray F, Center MM, Ferlay J, Ward E, Forman D. Global cancer statistics. CA Cancer J Clin. 2011;61:69-90.

2. Pecorelli S. Revised FIGO staging for carcinoma of the vulva, cervix, and endometrium. Int J Gynaecol Obstet. 2009;105:103-104.

3. Yang L, Douple EB, O'Hara JA, Crabtree RA, Eastman A. Enhanced radiation-induced cell killing by carboplatin in cells of repair-proficient and repair-deficient cell lines. Radiat Res. 1995;144:230-236.

4. Markman M. Chemoradiation in the management of cervix cancer: current status and future directions. Oncology. 2013;84:246-250.

5. Brock A, Prager W, Bohme R, Pohlmann S. The methods and results of simultaneous radiochemotherapy with carboplatin in advanced cervical carcinomas. Strahlenther Onkol. 1994;170:264-268. German.

6. Leath CA 3rd, Straughn JM Jr. Chemotherapy for advanced and recurrent cervical carcinoma: results from cooperative group trials. Gynecol Oncol. 2013;129:251-257.

7. Perez RP. Cellular and molecular determinants of cisplatin resistance. Eur J Cancer. 1998;34:1535-1542.

8. Shao J, Zhou B, Chu B, Yen Y. Ribonucleotide reductase inhibitors and future drug design. Curr Cancer Drug Targets. 2006;6:409-431.

9. Smith BD, Karp JE. Ribonucleotide reductase: an old target with new potential. Leuk Res. 2003;27:1075-1076.

10. Jordheim LP, Seve P, Tredan O, Dumontet C. The ribonucleotide reductase large subunit (RRM1) as a predictive factor in patients with cancer. Lancet Oncol. 2011;12:693-702.

11. Heinemann V, Xu YZ, Chubb S, et al. Inhibition of ribonucleotide reduction in CCRF-CEM cells by $2^{\prime}, 2^{\prime}$-difluorodeoxycytidine. Mol Pharmacol. 1990;38:567-572.

12. Huang P, Chubb S, Hertel LW, Grindey GB, Plunkett W. Action of 2',2'-difluorodeoxycytidine on DNA synthesis. Cancer Res. 1991;51: 6110-6117.

13. Braakhuis BJ, Ruiz van Haperen VW, Welters MJ, Peters GJ. Scheduledependent therapeutic efficacy of the combination of gemcitabine and cisplatin in head and neck cancer xenografts. Eur J Cancer. 1995;31A: 2335-2340.
14. Burnett AF, Roman LD, Garcia AA, Muderspach LI, Brader KR, Morrow CP. A phase II study of gemcitabine and cisplatin in patients with advanced, persistent, or recurrent squamous cell carcinoma of the cervix. Gynecol Oncol. 2000;76:63-66.

15. Brewer CA, Blessing JA, Nagourney RA, McMeekin DS, Lele S, Zweizig SL. Cisplatin plus gemcitabine in previously treated squamous cell carcinoma of the cervix: a phase II study of the Gynecologic Oncology Group. Gynecol Oncol. 2006;100:385-388.

16. Steeper JR, Steuart CD. A rapid assay for CDP reductase activity in mammalian cell extracts. Anal Biochem. 1970;34:123-130.

17. Shao J, Zhou B, Zhu L, et al. Determination of the potency and subunit-selectivity of ribonucleotide reductase inhibitors with a recombinant-holoenzyme-based in vitro assay. Biochem Pharmacol. 2005;69:627-634.

18. Shao J, Zhou B, Zhu L, et al. In vitro characterization of enzymatic properties and inhibition of the $\mathrm{p} 53 \mathrm{R} 2$ subunit of human ribonucleotide reductase. Cancer Res. 2004;64:1-6.

19. Chou TC, Motzer RJ, Tong Y, Bosl GJ. Computerized quantitation of synergism and antagonism of taxol, topotecan, and cisplatin against human teratocarcinoma cell growth: a rational approach to clinical protocol design. J Natl Cancer Inst. 1994;86:1517-1524.

20. Kang MH, Wan Z, Kang YH, Sposto R, Reynolds CP. Mechanism of synergy of N-(4-hydroxyphenyl)retinamide and ABT-737 in acute lymphoblastic leukemia cell lines: Mcl-1 inactivation. J Natl Cancer Inst. 2008;100:580-595.

21. Vilmar A, Garcia-Foncillas J, Huarriz M, Santoni-Rugiu E, Sorensen JB. RT-PCR versus immunohistochemistry for correlation and quantification of ERCC1, BRCA1, TUBB3 and RRM1 in NSCLC. Lung Cancer. 2012;75:306-312.

22. Liu X, Zhou B, Xue L, et al. Ribonucleotide reductase subunits M2 and p53R2 are potential biomarkers for metastasis of colon cancer. Clin Colorectal Cancer. 2007;6:374-381.

23. Kim D, Jung W, Koo JS. The expression of ERCC1, RRM1, and BRCA1 in breast cancer according to the immunohistochemical phenotypes. J Korean Med Sci. 2011;26:352-359.

24. Wang LM, Lu FF, Zhang SY, Yao RY, Xing XM, Wei ZM. Overexpression of catalytic subunit M2 in patients with ovarian cancer. Chin Med J (Engl). 2012;125:2151-2156.

25. Kunos CA, Radivoyevitch T, Kresak A, et al. Elevated ribonucleotide reductase levels associate with suppressed radiochemotherapy response in human cervical cancers. Int $J$ Gynecol Cancer. 2012;22:1463-1469.

26. Gautam A, Li ZR, Bepler G. RRM1-induced metastasis suppression through PTEN-regulated pathways. Oncogene. 2003;22:2135-2142.

27. Morikawa T, Maeda D, Kume H, Homma Y, Fukayama M. Ribonucleotide reductase M2 subunit is a novel diagnostic marker and a potential therapeutic target in bladder cancer. Histopathology. 2010;57:885-892.

28. Morikawa T, Hino R, Uozaki H, et al. Expression of ribonucleotide reductase M2 subunit in gastric cancer and effects of RRM2 inhibition in vitro. Hum Pathol. 2010;41:1742-1748.

29. Liu X, Lai L, Wang X, et al. Ribonucleotide reductase small subunit M2B prognoses better survival in colorectal cancer. Cancer Res. 2011;71:3202-3213.

30. Okumura H, Natsugoe S, Yokomakura N, et al. Expression of p53R2 is related to prognosis in patients with esophageal squamous cell carcinoma. Clin Cancer Res. 2006;12:3740-3745.

31. Scatchard K, Forrest JL, Flubacher M, Cornes P, Williams C. Chemotherapy for metastatic and recurrent cervical cancer. Cochrane Database Syst Rev. 2012;10:CD006469.

32. Hernández P, Olivera P, Dueñas-Gonzalez A, et al. Gemcitabine activity in cervical cancer cell lines. Cancer Chemother Pharmacol. 2001;48:488-492.

33. Termrungruanglert W, Tresukosol D, Vasuratna A, Sittisomwong T, Lertkhachonsuk R, Sirisabya N. Neoadjuvant gemcitabine and cisplatin followed by radical surgery in (bulky) squamous cell carcinoma of cervix stage IB2. Gynecol Oncol. 2005;97:576-581. 
34. Smith J, Tho LM, Xu N, Gillespie DA. The ATM-Chk2 and ATRChk1 pathways in DNA damage signaling and cancer. Adv Cancer Res. 2010;108:73-112.

35. Furgason JM, Bahassi el M. Targeting DNA repair mechanisms in cancer. Pharmacol Ther. 2013;137:298-308.

36. Kunos CA, Radivoyevitch T, Pink J, et al. Ribonucleotide reductase inhibition enhances chemoradiosensitivity of human cervical cancers. Radiat Res. 2010;174:574-581.

37. Moufarij MA, Phillips DR, Cullinane C. Gemcitabine potentiates cisplatin cytotoxicity and inhibits repair of cisplatin-DNA damage in ovarian cancer cell lines. Mol Pharmacol. 2003;63:862-869.
38. Nasr FL, Chahine GY, Kattan JG, et al. Gemcitabine plus carboplatin combination therapy as second-line treatment in patients with relapsed breast cancer. Clin Breast Cancer. 2004;5:117-122.

39. Monk BJ, Sill MW, McMeekin DS, et al. Phase III trial of four cisplatincontaining doublet combinations in stage IVB, recurrent, or persistent cervical carcinoma: a Gynecologic Oncology Group study. J Clin Oncol. 2009;27:4649-4655.

\section{Publish your work in this journal}

OncoTargets and Therapy is an international, peer-reviewed, open access journal focusing on the pathological basis of all cancers, potential targets for therapy and treatment protocols employed to improve the management of cancer patients. The journal also focuses on the impact of management programs and new therapeutic agents and protocols on

\section{Dovepress}

patient perspectives such as quality of life, adherence and satisfaction The manuscript management system is completely online and includes a very quick and fair peer-review system, which is all easy to use. Visit http://www.dovepress.com/testimonials.php to read real quotes from published authors.

\footnotetext{
Submit your manuscript here: http://www.dovepress.com/oncotargets-and-therapy-journal
} 